\title{
Inhalatory suchego proszku w dobie pandemii COVID-19 - co jest ważne dla pacjenta?
}

\section{Dry powder inhalers in the time of the COVID-19 pandemic - what is important for the patient?}

\section{Andrzej Emeryk1, Justyna Emeryk-Maksymiuk2 ${ }^{2}$ Kamil Janeczek', Karolina Grzywna ${ }^{3}$} ${ }^{1}$ Klinika Chorób Płuc i Reumatologii Dziecięcej, Uniwersytet Medyczny w Lublinie Kierownik Kliniki: prof. dr hab. n. med. Andrzej Emeryk

2 Katedra i Zakład Pielęgniarstwa Internistycznego, Uniwersytet Medyczny w Lublinie Kierownik Katedry: dr hab. n. med. Agnieszka Zwolak ${ }^{3}$ Studentka Wydziału Nauk Medycznych w Zabrzu, Koło Naukowe przy Katedrze i Zakładzie Patomorfologii, Śląski Uniwersytet Medyczny w Katowicach

\begin{abstract}
Streszczenie:
W artykule przedstawiono możliwości terapii inhalacyjnej astmy za pomocą inhalatorów suchego proszku w dobie pandemii COVID-19. Zwrócono uwagę na inhalatory suchego proszku obecne na polskim rynku zawierające kombinację glikokortykosteroidów wziewnych z długo działającym $\beta_{2}$-mimetykiem. Pokazano podobieństwa i różnice między różnymi DPI, akcentując cechy, które są ważne z punktu widzenia pacjenta. Szczegótowo omówiono inhalator Forspiro ${ }^{\circledR}$, który ma unikalne mechanizmy kontroli używania i poprawności techniki inhalacji, ważne dla chorego w dobie pandemii COVID-19 i teleporad medycznych.
\end{abstract}

\section{Abstract:}

Possibilities of asthma inhalation therapy with the use of dry powder inhalers in the time of the COVID-19 pandemic are presented. The attention was paid to the dry powder inhalers present on the Polish market containing a combination of inhaled corticosteroids with a long-acting $\beta_{2}$ agonist. The similarities and differences between different DPIs are shown, highlighting the features that are important from the patient's point of view. A detailed overview of the Forspiro ${ }^{\circledR}$ inhaler, which has unique mechanisms of taking over the control and correctness of the inhalation technique, important for the patient in the time of the COVID-19 pandemic and medical tele-advice.

Słowa kluczowe: inhalatory suchego proszku, inhalator Forspiro ${ }^{\circledR}$, COVID-19, astma, POChP, glikokortykosteroidy wziewne, długo działający $\beta_{2}$-mimetyk, terapia SMART

Key words: dry powder inhalers, Forspiro ${ }^{\circledR}$ inhaler, COVID-19, asthma, COPD, inhaled glucocorticosteroids, long-acting $\beta_{2}$ agonist, SMART therapy

Terapia inhalacyjna w dobie pandemii COVID-19

Pandemia COVID-19 zwróciła ponownie uwagę na bezpieczeństwo wszelkich procedur związanych $\mathrm{z}$ aerozolami medycznymi [1], szczególnie prowadzonych $\mathrm{w}$ zamkniętych placówkach opieki zdrowotnej. Zalecenia międzynarodowych, a także polskich grup ekspertów wskazują, iż terapia przewlekłych chorób układu oddechowego, takich jak astma czy przewlekła obturacyjna choroba płuc (POChP), w dobie COVID-19 powinna się opierać na skutecznej i bezpiecznej aerozoloterapii $[2,3]$. Pośród różnych metod inhalacji najbezpieczniejsze dla otoczenia są 
inhalatory suchego proszku (DPI, dry powder inhaler) oraz inhalatory ciśnieniowe dozujące (pMDI, pressurised metered dose inhalers) i to one powinny stanowić pierwszy wybór, zanim zapadnie decyzja o nebulizacji $[2,4]$. Wynika to z bardzo małego ryzyka rozsiewu bioaerozolu oraz łatwej dezynfekcji DPI i pMDI przy wysokiej efektywności klinicznej leków inhalowanych z tych urządzeń [5]. Dotyczy to szczególnie najnowszych DPI drugiej i trzeciej generacji [6]. Należy też pamiętać, iż ryzyko kontaminacji w przypadku DPI kapsułkowych (pierwsza generacja) jest wyższe niż w przypadku DPI blistrowego czy rezerwuarowego (druga generacja) [7]. Szczegółowy algorytm doboru inhalatora, w tym nebulizatorów u chorych na COVID-19 lub podejrzanych o tę chorobę, przedstawili niedawno Emeryk i wsp. [8].

\section{Przegląd najczęściej stosowanych DPI} zawierających kombinację glikokortykosteroidów wziewnych $z$ długo działającym $\beta_{2}$-mimetykiem

Zdecydowana większość chorych na astmę wymaga przewlekłej, codziennej terapii glikokortykosteroidami wziewnymi (wGKS) lub kombinacją tych leków z długo działającym $\beta_{2}$-mimetykiem (LABA, long acting $\beta$ agonists) [9]. Także część pacjentów z POChP ma wskazania do terapii wGKS z LABA [10]. Leki te są dostępne zarówno w pMDI, jak i w różnych DPI (kapsułkowe, blistrowe, rezerwuarowe). Inhalatory DPI różnią się znacznie między sobą wieloma elementami konstrukcji, sposobem użytkowania czy charakterystyką produkowanej chmury aerozolowej leków. W tabelach 1 i 2 przedstawiono wybrane parametry charakteryzujące DPI zawierające połącze-

Tabela 1. Najważniejsze parametry charakteryzujace DPI zawierajace połaczenie wGKS z LABA oraz produkowane przez nie chmury aerozolowe leków (na podstawie [11-24]).

\begin{tabular}{|c|c|c|c|c|c|c|}
\hline $\begin{array}{l}\text { Inhalator wGKS+ } \\
\text { LABA DN w } \mu g\end{array}$ & Typ inhalatora & $\begin{array}{l}\text { Optymalny prze- } \\
\text { phyw wdechowy } \\
\text { (I/min) }\end{array}$ & $\begin{array}{l}\text { Opór wewnętrzny } \\
\text { inhalatora }\end{array}$ & $\begin{array}{l}\text { MMAD } \\
(\mu \mathrm{m})^{\mathrm{a}}\end{array}$ & $\begin{array}{c}\text { FPF } \\
(\% \mathrm{DE})^{\mathrm{a}}\end{array}$ & $\begin{array}{c}\text { Zależność FPF od PIF w przedziale } \\
30-90 \text { I/min lub od spadku ciśnienia } \\
\text { w przedziale 2-6 kPa }\end{array}$ \\
\hline $\begin{array}{c}{\text { Breezhaler }{ }^{\circledR} \text { FM/IDA }}_{127,5 / 150}\end{array}$ & $\begin{array}{l}\text { jednodawkowy } \\
\text { kapsułkowy }\end{array}$ & $50-100$ & niski & $\begin{array}{l}\mathrm{FM}-2,7 \\
\text { IDA }-2,6\end{array}$ & $\begin{array}{l}\text { FM }-45 \\
\text { IDA }-45\end{array}$ & względnie stała \\
\hline $\begin{array}{c}\text { Dysk }^{\circledast} \mathrm{PF} / \mathrm{SAL} \\
250 / 50\end{array}$ & $\begin{array}{c}\text { wielodawkowy } \\
\text { blistrowy }\end{array}$ & $30-90$ & średnioniski & $\begin{array}{c}\mathrm{PF}-3,9 \\
\mathrm{SAL}-4,1\end{array}$ & $\begin{array}{c}P F-23 \\
S A L-40\end{array}$ & względnie stała \\
\hline $\begin{array}{c}G 7^{\oplus} \text { b Dysk } \\
\text { generyczny PF/SAL } \\
250 / 50\end{array}$ & $\begin{array}{l}\text { wielodawkowy } \\
\text { blistrowy }\end{array}$ & $30-90$ & średnioniski & $\begin{array}{c}\mathrm{PF}-3,5 \\
\mathrm{SAL}-3,2\end{array}$ & $\begin{array}{c}\text { PF }-24,6 \\
S A L-21,4\end{array}$ & względnie stała \\
\hline $\begin{array}{c}\text { Aerostar }^{\circledR} \text { b Dysk } \\
\text { generyczny PF/SAL } \\
250 / 50\end{array}$ & $\begin{array}{l}\text { wielodawkowy } \\
\text { blistrowy }\end{array}$ & $30-90$ & średnioniski & $\begin{array}{c}\mathrm{PF}-4,2 \\
\mathrm{SAL}-3,5\end{array}$ & $\begin{array}{c}\text { PF }-22,1 \\
\text { SAL }-22,9\end{array}$ & względnie stała \\
\hline $\begin{array}{c}{\text { Easyhaler }{ }^{\circledR} \mathrm{PF}+\mathrm{SAL}}_{250 / 50}\end{array}$ & $\begin{array}{l}\text { wielodawkowy } \\
\text { rezerwuarowy }\end{array}$ & $28-60$ & średnioniski & $\begin{array}{c}P F-2,82 \\
S A L-2,55\end{array}$ & bd & rosnąca \\
\hline $\begin{array}{c}\text { Easyhaler }^{\circledast} \text { BUD/ } \\
\text { FOR }^{\star} 160 / 4,5\end{array}$ & $\begin{array}{l}\text { wielodawkowy } \\
\text { rezerwuarowy }\end{array}$ & $28-60$ & średnioniski & $\begin{array}{l}\text { BUD }-2,8 \\
\text { FOR }-2,7\end{array}$ & $\begin{array}{l}\text { BUD }-43 \\
\text { FOR }-41\end{array}$ & rosnąca \\
\hline $\begin{array}{l}\text { Ellipta }{ }^{\circledR} \text { FF/WIL } \\
\quad 100 / 25\end{array}$ & $\begin{array}{c}\text { wielodawkowy } \\
\text { blistrowy }\end{array}$ & $43-130$ & średniowysoki & $\begin{array}{c}\mathrm{FF}-4,0 \\
\mathrm{WIL}-2,3\end{array}$ & $\begin{array}{c}\mathrm{FF}-25 \\
\mathrm{WIL}-37\end{array}$ & stała \\
\hline $\begin{array}{c}\text { Elpenhaler }{ }^{\circledast} \mathrm{PF}+\mathrm{SAL} \\
250 / 50\end{array}$ & $\begin{array}{l}\text { wielodawkowy } \\
\text { blistrowy }\end{array}$ & $\mathrm{bd}$ & średnioniski & $\begin{array}{c}P F-3,33 \\
S A L-2,88\end{array}$ & $\begin{array}{c}\text { PF }-16,9 \\
S A L-14,3\end{array}$ & względnie stała \\
\hline $\begin{array}{c}\text { Forspiro }^{\circledR} \mathrm{PF} / \mathrm{SAL} \\
250 / 50\end{array}$ & $\begin{array}{l}\text { wielodawkowy } \\
\text { blistrowy }\end{array}$ & $42-134$ & średnioniski & bd & bd & względnie stała \\
\hline $\begin{array}{c}\text { Forspiro }{ }^{\oplus} \text { BUD/ } \\
\text { FOR }^{*} 160 / 4,5\end{array}$ & $\begin{array}{l}\text { wielodawkowy } \\
\text { blistrowy }\end{array}$ & $42-134$ & średnioniski & bd & $\begin{array}{c}\text { BUD }-44 \text { c } \\
\text { FOR }-36\end{array}$ & względnie stała \\
\hline $\begin{array}{l}\text { Nexthaler }{ }^{\circledR} \text { BDP/ } \\
\text { FOR }^{*} 100 / 6,0\end{array}$ & $\begin{array}{l}\text { wielodawkowy } \\
\text { rezerwuarowy }\end{array}$ & $30-100$ & średniowysoki & $\begin{array}{l}\text { BDP }-1,1 \\
\text { FOR }-1,7\end{array}$ & $\begin{array}{l}\text { BDP }-57 \\
\text { FOR }-55\end{array}$ & stała \\
\hline $\begin{array}{c}\text { Spiromax }{ }^{\circledast} \text { BUD/ } \\
\text { FOR }^{*} 160 / 4,5\end{array}$ & $\begin{array}{l}\text { wielodawkowy } \\
\text { rezerwuarowy }\end{array}$ & $40-90$ & średniowysoki & $\begin{array}{l}\text { BUD }-2,2 \\
\text { FOR }-2,2\end{array}$ & $\begin{array}{l}\text { BUD }-47 \\
\text { FOR }-45\end{array}$ & stała \\
\hline $\begin{array}{c}\text { Turbuhaler }{ }^{\circledast} \text { BUD/ } \\
\text { FOR }^{*} 160 / 4,5\end{array}$ & $\begin{array}{l}\text { wielodawkowy } \\
\text { rezerwuarowy }\end{array}$ & $60-90$ & średniowysoki & $\begin{array}{l}\text { BUD }-2,1 \\
\text { FOR }-2,1\end{array}$ & $\begin{array}{l}\text { BUD - } 62 \\
\text { FOR - } 63\end{array}$ & rosnąca \\
\hline
\end{tabular}

bd - brak danych; BDP - dipropionian beklometazonu; BUD - budezonid; DE - dawka emitowana; FF- furoinian flutykazonu; FM - furoinian mometazonu; FOR - formoterol; FPF (fine particle fraction) - frakcja cząstek drobnych; IDA - indakaterol; LABA (long acting $\beta$ agonists) - długo działający $\beta_{2}$-mimetyk; MMAD (median mass aerodynamic diameter) - średnica aerodynamiczna czastki odpowiadajaca medianie rozkładu masowego; PF - propionian flutykazonu; PIF (peak inspiratory flow) - szczytowy przepływ wdechowy; SAL - salmeterol; wGKS - glikokortykosteroid wziewny; WIL - wilanterol.

* Połączenia wGKS + LABA i inhalatory zarejestrowane w terapii SMART (Single Maintenance and Reliever Therapy); ${ }^{\text {a }}$ wartości badane przy objętości 4 I i spadku ciśnienia $4 \mathrm{kPa}{ }^{\text {b }}$ dotyczy DE, a nie FPF; ${ }^{c}$ dane firmy Sandoz. 
Tabela 2. Rzadziej przedstawiane parametry charakteryzujace DPI zawierajace połaczenie wGKS z LABA (na podstawie [25-35]).

\begin{tabular}{|c|c|c|c|c|c|}
\hline $\begin{array}{l}\text { Inhalator wGKS + } \\
\text { LABA DN ( } \mu g)\end{array}$ & $\begin{array}{l}\text { Zawartość lakto- } \\
\text { zy w DN (mga) }\end{array}$ & $\begin{array}{l}\text { Odsetek } \\
\text { DE do DNa }\end{array}$ & $\begin{array}{l}\text { Wpływ pozycji inhala- } \\
\text { tora na wielkość DEa }\end{array}$ & $\begin{array}{l}\text { Okres ważności/okres } \\
\text { ważności po otwarciua }\end{array}$ & Ślad węglowy $\left(\mathrm{kg} \mathrm{CO}_{2}{ }^{\mathrm{e}}\right)$ \\
\hline $\begin{array}{c}\text { Breezhaler }^{\circledast} \\
\text { FM + IDA 127,5/150 }\end{array}$ & 25 & $\begin{array}{l}\text { FM: } 83 \\
\text { IDA: } 80\end{array}$ & $(++)$ & 30 miesięcy & 0,4 na 1 miesiąc stosowania inhalatora \\
\hline $\begin{array}{c}\text { Dysk }^{\circledast} \\
\mathrm{PF}+\text { SAL 250/50 }\end{array}$ & 12,5 & $\begin{array}{l}\text { PF: } 94 \\
\text { SAL: } 94\end{array}$ & $(+)$ & 2 lata/bd & $\begin{array}{c}\text { 1,09 na } 1 \text { miesiąc stosowania inhalatora } \\
\text { zawierającego } 60 \text { dawek }\end{array}$ \\
\hline $\begin{array}{c}\text { Dyski generyczne G7 } \\
\text { i Aerostar } \\
\text { PF + SAL 250/50 }\end{array}$ & 13,3 & $b d$ & $(+)$ & 18 miesięcy & $b d$ \\
\hline $\begin{array}{c}\text { Easyhaler }^{\circledR} \\
\text { PF + SAL 250/50 }\end{array}$ & 17,1 & $\begin{array}{l}\text { PF: } 91 \\
\text { SAL: } 88\end{array}$ & $(++)$ & 2 lata/1 miesiąc & 0,6 na inhalator zawierający 60 dawek \\
\hline $\begin{array}{c}\text { Easyhaler }{ }^{\circledR} \\
\text { BUD }^{\circledR} \text { FOR }^{*} \text { 160/4,5 }\end{array}$ & 3,8 & ok. 100 & $(++)$ & 2 lata/4 miesiące & 0,57 na inhalator zawierający 120 dawek \\
\hline $\begin{array}{c}\text { Ellipta }^{\circledR} \\
\text { FF + WIL 100/25 }\end{array}$ & ok. 25 & $\begin{array}{l}\text { FF: } 92 \\
\text { WIL: } 88\end{array}$ & $(+)$ & 2 lata/6 tygodni & $\begin{array}{c}\text { 0,8 na } 1 \text { miesiąc stosowania inhalatora } \\
\text { (60 dawek) }\end{array}$ \\
\hline $\begin{array}{c}\text { Elpenhaler } \\
\text { PF + SAL 250/50 }\end{array}$ & 24,7 & $\begin{array}{l}\text { PF: } 79 \\
\text { SAL: } 82\end{array}$ & $(+)$ & 2 lata/bd & bd \\
\hline $\begin{array}{c}\text { Forspiro }^{\circledR} \\
\text { PF + SAL 250/50 }\end{array}$ & 12,2 & $\begin{array}{l}\text { PF: } 93 \\
\text { SAL: } 90\end{array}$ & ( & 2 lata & bd \\
\hline $\begin{array}{c}\text { Forspiro }^{\circledR} \\
\text { BUD }^{\circledR} \text { FOR }^{\star} 160 / 4,5\end{array}$ & 5,4 & $\begin{array}{l}\text { BUD: } 82 \\
\text { FOR: } 74\end{array}$ & $(-)$ & 2 lata & $b d$ \\
\hline $\begin{array}{l}\text { Nexthaler }^{\circledR} \text { BDP }+ \\
\text { FOR }^{*} 100 / 6,0\end{array}$ & 9,9 & $\begin{array}{l}\text { BDP: } 82 \\
\text { FOR: } 83\end{array}$ & $(+)$ & 3 lata/6 miesięcy & $\begin{array}{l}0,92 \text { na } 1 \text { inhalator zawierający } \\
120 \text { dawek }\end{array}$ \\
\hline $\begin{array}{l}\text { Spiromax }{ }^{\oplus} \text { BUD }+ \\
\text { FOR }^{\star} 160 / 4,5\end{array}$ & ok. 5 & $\begin{array}{l}\text { BUD: } 80 \\
\text { FOR: } 75\end{array}$ & $(+)$ & 3 lata/6 miesięcy & $\begin{array}{l}\text { ok. } 1 \text { na } 1 \text { inhalator zawierający } \\
120 \text { dawek }\end{array}$ \\
\hline $\begin{array}{l}\text { Turbuhaler }^{\circledast} \text { BUD + } \\
\text { FOR }{ }^{*} 160 / 4,5\end{array}$ & 0,7 & $\begin{array}{l}\text { BUD: } 80 \\
\text { FOR: } 75\end{array}$ & $(++)$ & 2 lata & $\begin{array}{l}\text { ok. } 1 \text { na } 1 \text { inhalator zawierający } \\
120 \text { dawek }\end{array}$ \\
\hline
\end{tabular}

bd - brak danych; BDP - dipropionian beklometazonu; BUD - budezonid; DE - dawka emitowana; DN - dawka nominalna; FF - furoinian flutykazonu; FM - furoinian mometazonu; FOR - formoterol; IDA - indakaterol; LABA - długo działający $\beta_{2}$-mimetyk; PF - propionian flutykazonu; SAL - salmeterol; wGKS - glikokortykosteroid wziewny; WIL - wilanterol.

(+) - wpływ niewielki; (++) - wpływ znaczący; (-) - brak wpływu; a na podstawie charakterystyki produktów leczniczych.

nie wGKS z LABA w jednym inhalatorze (inhalatory podano w kolejności alfabetycznej) dla dawek średnich wGKS.

Forspiro $^{\circledR}$ jest jedynym obok Easyhalera $^{\circledR}$ w Polsce oryginalnym inhalatorem zawierającym dwa rodzaje kombinacji wGKS + LABA: propionian flutykazonu + salmeterol $(\mathrm{PF}+\mathrm{SAL})$ oraz budezonid + formoterol (BUD + FOR). Obie kombinacje mogą być użyte w terapii „sztywnej” astmy, a połączenie BUD z FOR także w terapii typu SMART (Single Maintenance and Reliever Therapy) (tab. 1). Stanowi to duże ułatwienie dla lekarza i chorych na astmę wymagających wdrożenia metody SMART, a dotychczas leczonych np. kombinacją PF + SAL z inhalatora Forspiro ${ }^{\circledR}$ [9]. Ma to istotne znaczenie $\mathrm{w}$ dobie pandemii COVID-19 łączącej się z ograniczonym dostępem do lekarza, także specjalisty, oraz do edukacji prowadzonej „na żywo”. Inhalator Forspiro ${ }^{\circledR}$ ma jeden z najwyższych odsetków dawki emitowanej (DE) w odniesieniu do dawki nominalnej (DN), co wskazuje na jego dużą sprawność na tle innych DPI. Forspiro ${ }^{\circledR}$ cechuje, po- dobnie jak większość nowoczesnych DPI, średnioniski opór wewnętrzny. Ma też najszerszy, obok Ellipty ${ }^{\circledR}$, zakres optymalnych przepływów wdechowych, co jest bardzo ważne $\mathrm{z}$ punktu widzenia chorego. Te dwa elementy decydują istotnie o zainhalowaniu przez chorego właściwej dawki leku w oczekiwanej (zgodnej z charakterystyką produktu leczniczego) chmurze aerozolowej, niezależnie od możliwości wygenerowania przepływów niskich (30-50 1/min) czy wysokich (120-140 1/min). Ta cecha stanowi o istotnej przewadze Forspiro ${ }^{\circledR}$ nad takimi DPI jak Turbuhaler ${ }^{\circledR}$ czy Easyhaler ${ }^{\circledR}$. Innymi zaletami Forspiro ${ }^{\circledR}$ z BUD + FOR są stosunkowo niewielka (na tle innych DPI) zawartość laktozy oraz prawidłowe działanie i odmierzanie dawki leku niezależnie od pozycji trzymania inhalatora [36].

\section{DPI - punkt widzenia chorego}

Inhalatory są ciągle często źle używane, a chorzy w wielu krajach świata [37, 38], także w Polsce [39], 
wymagają intensywnego szkolenia. Trudności związane $\mathrm{z}$ prawidłowym używaniem inhalatorów negatywnie wpływają na wyniki leczenia i zwiększają koszty terapii tych pacjentów, którzy posługują się złą techniką inhalacji [40-42].

Prawidłowo przeprowadzony wybór inhalatora, w tym DPI uwzględniający preferencje użytkownika, może wspierać optymalną kontrolę choroby [43, 44]. Innowacyjne DPI mogą się przyczynić do poprawy techniki inhalacji u chorych, a także poprawy adherencji i osiągnięcia kontroli choroby, prowadząc tym samym do lepszej alokacji zasobów opieki zdrowotnej [45]. Jednym z najnowszych DPI spełniających te warunki jest inhalator Forspiro ${ }^{\circledR}$ - wielodawkowy, blistrowy DPI drugiej generacji, będący twórczym rozwinięciem DPI typu GyroHaler ${ }^{\circledR}[31,46]$. Forspiro ${ }^{\circledR}$ ma szereg unikalnych i/lub bardzo ważnych cech zbliżających go do ,inhalatora idealnego" [15]. Przedstawiono je w tabeli 3. Najważniejsze z nich z punktu widzenia chorego to:

- poręczność (mały ciężar i wymiary, np. jest znacznie lżejszy niż Dysk ${ }^{\circledR}$ )

- intuicyjna obsługa (większość osób użyje go poprawnie w sposób intuicyjny)

- niski minimalny przypływ wdechowy (30 1/min), który jest osiągalny przez chorych na astmę o różnym stopniu ciężkości (w tym dzieci $>4$. r.ż.) oraz pacjentów nawet $\mathrm{z}$ ciężkimi postaciami POChP

- brak wpływu różnych pozycji trzymania inhalatora na wyzwalaną dawkę

- niewielka siła potrzebna do otwarcia inhalatora i przebicia blistra (ważna cecha dla chorych na POChP)
- kilka mechanizmów zwrotnych informujących chorego o dawkowaniu, w tym możliwość wizualnego sprawdzenia blistra

- najlepsze z możliwych zabezpieczenie przed wilgocią

- dość niska cena.

Łatwość w pierwszym użyciu i zminimalizowanie ryzyka błędów podczas inhalacji to ważne cechy inhalatorów stosowanych $\mathrm{w}$ trakcie pandemii COVID-19 w sytuacji odbywania większości wizyt zdalnie. Jak wynika $\mathrm{z}$ danych zawartych w tabeli 3, konstrukcja i działanie inhalatora Forspiro ${ }^{\circledR}$ sa nakierowane na pacjenta, ułatwiając wykonanie kolejnych czynności podczas inhalacji. Inhalator wymaga jedynie trzech kroków przed zainhalowaniem leku. Jest też tak skonstruowany, że uniemożliwia wykonanie kolejnej czynności w procesie jego używania przed wykonaniem właściwego kroku poprzedniego. Dzieje się tak dlatego, iż był to jeden z nielicznych DPI, przy którego konstrukcji wzięto pod uwagę opinie i uwagi chorych [50]. To spowodowało, iż rozwiązania zastosowane w Forspiro ${ }^{\circledR}$ są proste, jasne i zrozumiałe dla użytkowników.

Forspiro $^{\circledR}$ ma unikalne mechanizmy kontroli używania i poprawności techniki inhalacji, niezmiernie ważne z punktu widzenia chorego. Pacjent używający tego inhalatora słyszy kliknięcia potwierdzające poprawne otwarcie i zamknięcie urządzenia oraz ustnika. Użytkownik inhalatora widzi też ruch blistra z lekiem i numer kolejnej dawki po jej załadowaniu. A zatem otrzymuje informację, iż właściwie załadował dawkę leku, oraz widzi numer dawki leku, który przyjął.

Tabela 3. Zalety $i$ wady inhalatora Forspiro ${ }^{\circledR}$ (na podstawie [15, 47-50]).

\begin{tabular}{|c|c|c|}
\hline & Budowa i działanie inhalatora & Punkt widzenia chorego \\
\hline Zalety & $\begin{array}{l}\text { - } \text { niski minimalny przypływ wdechowy (30 l/min) } \\
\text { - bardzo wysoka powtarzalność emitowanych dawek } \\
\text { - } \text { szeroki przedział optymalnych przepływów wdechowych: } 42-134 \text { I/min } \\
\text { - } \text { niewielka zależność wyzwalanych dawek leków od wielkości przepły- } \\
\text { - wów wdechowych } \\
\text { - dokładna praca igły przebijającej blistry z lekiem przez cały okres używa- } \\
\text { nia inhalatora } \\
\text { - } \text { stałość oporu wewnętrznego w trakcie całego okresu używania inhala- } \\
\quad \text { tora } \\
\text { - optymalna ochrona proszku przed zawilgoceniem } \\
\text { - } \text { prosty i dokładny licznik dawek } \\
\text { - } \text { podlega pełnemu recyklingowi }\end{array}$ & $\begin{array}{l}\text { - } \text { poręczność (mały ciężar i wymiary) } \\
\text { - } \text { intuicyjna obsługa } \\
\text { - brak wpływu różnych pozycji trzymania inhalatora na wyzwalaną } \\
\text { - } \text { niewielka siła potrzebna do otwarcia inhalatora i przebicia blistra } \\
\text { - mechanizm samokontroli poprawnej techniki inhalacji (możli- } \\
\text { - wość wizualnego sprawdzenia blistra) } \\
\text { - kilka mechanizmów zwrotnych informujących chorego o daw- } \\
\text { - } \text { nowaniu } \\
\text { - } \text { nowoćzesny design } \\
\text { niska cena }\end{array}$ \\
\hline Wady & $\begin{array}{l}\text { - prawdopodobnie wysoka wartość MMAD } \\
\text { - prawdopodobnie niska wartość FPF }\end{array}$ & $\begin{array}{l}\text { - użycie inhalatora wymaga większej liczby kroków niż w przy- } \\
\text { padku innych DPI } \\
\text { - brak innych klas leków potrzebnych w terapii astmy lub POChP } \\
\text { (SABA, LAMA) }\end{array}$ \\
\hline
\end{tabular}

DPI (dry powder inhaler) - inhalator suchego proszku; FPF (fine particle fraction) - frakcja cząstek drobnych; LAMA (long acting muscarinic antagonists) - długo działający lek antymuskarynowy; MMAD (median mass aerodynamic diameter) - średnica aerodynamiczna cząstki odpowiadająca medianie rozkładu masowego; POChP - przewlekła obturacyjna choroba płuc; SABA (short acting $\beta$ agonists) - krótko działający $\beta_{2}$-mimetyk. 
Ponadto ma możliwość wizualnej kontroli wykorzystanych pasków blistra, co upewnia go kolejny raz o poprawnym zastosowaniu inhalatora. Elementy formy inhalatora oraz wzrokowe i dotykowe wskazówki pomagają prowadzić chorego w kolejnych krokach użycia urządzenia nawet bez uprzedniej edukacji $[36,50]$.

Te cechy Forpsiro ${ }^{\circledR}$ mają szczególne znaczenie w dobie pandemii COVID-19 - pacjent może samodzielnie sprawdzić w domu, czy wykonał inhalację poprawnie. Stąd inhalator Forspiro ${ }^{\circledR}$ jest wybitnie przyjazny dla chorych na astmę czy POChP, co potwierdzają badania akceptacji i adherencji tego urządzenia [51].

\section{Podsumowanie}

Inhalatory suchego proszku są najpopularniejszymi indywidualnymi urządzeniami inhalacyjnymi. Ta grupa inhalatorów jest wysoce zróżnicowana pod względem takich cech, jak: opór wewnętrzny, charakter produkowanej chmury aerozolowej (MMAD, FPF), zależność frakcji cząstek drobnych (FPF, fine particle fraction) od szczytowego przepływu wdechowego (PIF, peak inspiratory flow), zawartość laktozy, odsetek DE w odniesieniu do DN czy wielkość śladu węglowego. Różnicuje je także sposób używania i ryzyko popełnienia błędów w trakcie korzystania z urządzeń. Forspiro $^{\circledR}$ jest inhalatorem wielodawkowym, blistrowym, o średnioniskim oporze wewnętrznym, zawierającym połączenie propionianu flutykazonu $\mathrm{z}$ salmeterolem lub budezonidu $\mathrm{z}$ formoterolem, co umożliwia leczenie chorych na astmę także metodą SMART. Cechuje się najszerszym zakresem optymalnych przepływów wdechowych (42-134 1/min) pośród dostępnych DPI przy minimalnym przepływie wdechowym rzędu 30 1/min. Większość pacjentów posłuży się tym inhalatorem poprawnie w sposób intuicyjny. Forspiro ${ }^{\circledR}$ ma unikalne mechanizmy kontroli używania i poprawności techniki inhalacji, ważne $\mathrm{z}$ punktu widzenia chorego w dobie pandemii COVID-19 i teleporad medycznych.

\section{Piśmiennictwo}

1. Tran K, Cimon K, Severn M et al. Aerosol generating procedures and risk of transmission of acute respiratory infections to healthcare workers: A systematic review. PLoS ONE. 2012; 7(4): e35797.

2. Shaker MS, Oppenheimer J, Grayson $M$ et al. COVID-19: pandemic contingency planning for the allergy and immunology clinic. J Allergy Clin Immunol Pract. 2020; 8(5): 1477-88.
3. Kowalski ML, Bartuzi Z, Bręborowicz A et al. Stanowisko grupy ekspertów Polskiego Towarzystwa Alergologicznego $w$ sprawie postępowania $u$ chorych na astmę $i$ choroby alergiczne w okresie pandemii SARS-CoV-2. Alergologia Polska - Polish Journal of Allergology. 2020; 7(2): 1-7.

4. McGrath JA, O'Sullivan A, Bennett $G$ et al. Investigation of the quantity of exhaled aerosols released into the environment during nebulization. Pharmaceutics. 2019; 11(2): 75.

5. Ari A. Practical strategies for a safe and effective delivery of aerosolized medications to patients with COVID-19 Respir Med. 2020; 167: 105987. http://doi.org/10.1016/j.rmed.2020. 105987.

6. Emeryk A, Pirożyński M, Mazurek H et al. Polski przewodnik inhalacyjny. $2^{\text {nd }}$ ed. Via Medica, Gdańsk 2021: 1-48.

7. Pirożyński M. Terapia wziewna ze szczególnym uwzględnieniem steroidów w okresie pandemii COVID-19. Alergia. 2020; 1: 4-6.

8. Emeryk A, Pirożyński M, Mazurek $H$ et al. Stanowisko polskich ekspertów dotyczące nebulizacji $w$ okresie pandemii COVID-19. Terapia. 2020; 28: 12-8.

9. Global Strategy for Asthma Management and Prevention, Global Initiative for Asthma (GINA). Update 2020. https://ginasthma.org/wp-content/uploads/2020/06/GINA-2020-mainreport-June-2020-wms.pdf (access: 30.12.2020).

10. Global Strategy for the Diagnosis, Management, and Prevention of Chronic Obstructive Pulmonary Disease 2020 Report. https://goldcopd.org/wp-content/uploads/2019/11/GOLD2020-REPORT-ver1.0wms.pdf (access: 30.12.2020).

11. Haidl $P$, Heindl S, Siemon $K$ et al. Inhalation device requirements for patients inhalation maneuvers. Respir Med. 2016; 118: 65-75.

12. Emeryk A, Pirożyński M. Nowe inhalatory suchego proszku. Pneumonol Alergol Pol. 2015; 83: 83-7.

13. Grant AC, Walker R, Hamilton $M$ et al. The ELLIPTA ${ }^{\circledR}$ dry powder inhaler: design, functionality, in vitro dosing performance and critical task compliance by patients and caregivers. J Aerosol Med Pulm Drug Deliv. 2015; 28(6): 474-85.

14. Canonica GW, Arp J, Keegstra JR et al. Spiromax, a new dry powder inhaler: dose consistency under simulated real-world conditions. J Aerosol Med Pulm Drug Deliv. 2015; 28: 309-19.

15. Emeryk A, Pirożyński M. Forspiro - nowy inhalator suchego proszku. Czy zbliżamy się do ideatu? Pneumonol Alergol Pol. 2016; 84(6): 64-9.

16. Lavorini F, Janson Ch, Braido F et al. What to consider before prescribing inhaled medications: a pragmatic approach for evaluating the current inhaler landscape. Ther Adv Respir Dis. 2019; 13: 1753466619884532.

17. Lung deposition and particle size of Fluticasone Furoate/ vilanterol. Data on file. GKS 2014N188664_00.2014.

18. Chapman KR, Fogarty CM, Peckitt $C$ et al. Delivery characteristics and patients' handling of two single-dose dry powder 
inhalers used in COPD. Int $J$ Chron Obstruct Pulmon Dis. 2011; 6: 353-63.

19. Hoppentocht M, Hagedoorn P, Frijlink HW et al. Technological and practical challenges of dry powder inhalers and formulations. Adv Drud Deliv Rev. 2014; 75: 18-31.

20. Johal B, Howald M, Fischer $M$ et al. Fine particle profile of fluticasone propionatelformoterol fumarate versus other combination products: the DIFFUSE Study. Comb Prod Ther. 2013; 3: 39-51.

21. Demoly P, Hagedoorn P, de Boer AH et al. The clinical relevance of dry powder inhaler performance for drug delivery. Respir Med. 2014; 108(8): 1195-203.

22. de Boer AH, Gjaltema D, Hagedoorn P et al. Can extrafine dry powder aerosols improve lung deposition? Eur J Pharm Biopharm. 2015; 96: 143-51.

23. Turpeinen A, Eriksson P, Happonen A et al Consistent dosing through the salmeterol-fluticasone propionate Easyhaler for the management of asthma and chronic obstructive pulmonary disease: robustness analysis across the Easyhaler lifetime. J Aerosol Med Pulm Drug Deliv. 2020. http://doi. org/10.1089/jamp.2020.1592.

24. Jogi $R$, Lähelmä $S$, Vahteristo $M$ et al. In vitro flow rate dependency of delivered dose and fine particle dose of salmeterolffluticasone propionate Easyhaler and Seretide Diskus with patient flow rates collected in a randomized controlled trial. J Aerosol Med Pulm Drug Deliv. 2019; 32(2): 88-98.

25. Panigone S, Sandri F, Ferri R et al. Environmental impact of inhalers for respiratory diseases: decreasing the carbon footprint while preserving patient-tailored treatment. BMJ Open Resp Res. 2020; 7: e000571.

26. Product Carbon Footprint: Life Cycle Assessment Report for Orion Corporation, Orion Pharma. A study of 4 varieties of Easyhalers. Carbon Footprint Ltd 2020. https://www.orion. fi/en/Sustainability/stories-about-responsibility/inhaler-environmental-footprint/ (access: 25.12.2020).

27. https://www.propellerhealth.com/press/press-release/propeller-health-sensor-to-be-co-packaged-with-recently-approved-enerzair-breezhaler-asthma-medication-in-europe/ (access: 10.12.2020).

28. Wilkinson AJK, Braggins R, Steinbach I et al. Costs of switching to low global warming potential inhalers. An economic and carbon footprint analysis of NHS prescription data in England. BMJ Open. 2019; 9: e028763.

29. Janson Ch, Henderson R, Löfdahl M et al. Carbon footprint impact of the choice of inhalers for asthma and COPD. Thorax. 2020; 75(1): 82-4.

30. www.greeninhaler.org/inhaler-comparison/ (access: 30.12.2020).

31. Reece C, Swanbury PH. An Overview of the design verification testing process for the GyroHaler ${ }^{\circledR}$ dry powder inhaler. https://aerosol-soc.com/abstracts/overview-design-verifica- tion-testing-process-gyrohaler-dry-powder-inhaler) (access: 23.03.2021).

32. Tarsin WY, Pearson SB, Assi KH et al. Emitted dose estimates from Seretide Diskus and Symbicort Turbuhaler following inhalation by severe asthmatics. Int J Pharm. 2006; 316(1-2): 131-7.

33. Voshaar T, Spinola M, Linnane P et al. Comparing usability of NEXThaler with other inhaled corticosteroid/long-acting B2-agonist fixed combination dry powder inhalers in asthma patients. J Aerosol Med Pulm Drug Deliv. 2014; 27(5): 363-70.

34. Hill LS. A comparison of the performance of two modern multidose dry powder asthma inhalers. Respir Med. 1998; 92: 105-10.

35. Kondo T, Tanigaki T, Yokoyama H et al. Impact of holding position during inhalation on drug release from a reservoir-, blister- and capsule-type dry powder inhaler. J Asthma. 2017; 54(8): 792-7.

36. http://leki.urpl.gov.pl/files/49_Airbufo_Forspiro.pdf (access: 21.12.2020)

37. Sanchis J, Gich I, Pedersen S; on behalf of Aerosol Drug Management Improvement Team (ADMIT). Systematic review of errors in inhaler use: has patient technique improved over time? Chest. 2016; 150: 394-406.

38. Chrystyn $H$, van der Palen J, Sharma R et al. Device errors in asthma and COPD: systematic literature review and meta-analysis. NPJ Prim Care Respir Med. 2017; 27: 22.

39. Luczak-Wozniak K, Dabrowska M, Domagala I et al. Mishandling of pMDI and DPI inhalers in asthma and COPD Repetitive and non-repetitive errors. Pulm Pharmacol Ther. 2018; 51: 65-72.

40. Lavorini F, Usmani OS. Correct inhalation technique is critical in achieving good asthma control. Prim Care Respir J. 2013; 22: 385-6.

41. Usmani OS, Lavorini F, Marshall J et al. Critical inhaler errors in asthma and COPD: a systematic review of impact on health outcomes. Respir Res. 2018; 19: 10

42. Lewis A, Torvinen S, Dekhuijzen PNR et al. The economic burden of asthma and chronic obstructive pulmonary disease and the impact of poor inhalation technique with commonly prescribed dry powder inhalers in three European countries. BMC Health Serv Res. 2016; 16: 251-63.

43. Price D, Bosnic-Anticevich S, Briggs A et al. Inhaler competence in asthma: common errors, barriers to use and recommended solutions. Respir Med. 2013; 107: 37-46.

44. Emeryk A, Pirożyński M, Emeryk-Maksymiuk J. Dry powder inhalers - between the doctor and the patient. Adv Respir Med. 2018; 86(suppl I): 28-41.

45. Virchow JC, Akdis CA, Darba J et al. A review of the value of innovation in inhalers for COPD and asthma. J Mark Access Health Policy. 2015; 3: 1-8. 
46. https://citywire.co.uk/funds-insider/news/ace-vectura-leaps-on-inhaler-development/a261150 (access: 15.03.2021).

47. Jones $S$, Gath I, Weuthen T. Comparison of inspiratory flow rates using an innovative dry powder inhaler (DPI) in patients with mild-severe asthma and severe COPD. Eur Respir J. 2014; 44: P941.

48. Jones $S$, Weuthen T, Harmer QJ et al. P7 Assessing the intuitive ease of use a novel dry powder inhaler, the Forspiro device, for asthma and COPD. Thorax. 2012; 67: A66-A7.

49. Jones $S$, Clarke R, Eason $S$ et al. Comparison of an innovative multi-dose inhaler with the attributes of an 'ideal' inhaler: A multicentre, randomised controlled trial (RCT). Eur Respir J. 2014; 44: P937.

50. Virchow JC, Weuthen T, Harmer QJ et al. Identifying the features of an easy-to-use and intuitive dry powder inhaler for asthma and chronic obstructive pulmonary disease therapy: results from a 28-day device handling study, and an airflow resistance study. Expert Opin Drug Deliv. 2014; 11(12): 1849-57.

51. Backer V, Leif Bjermer L, Refvem OK et al. A multicenter, open-label, noninterventional study to evaluate the impact on clinical effects, userfriendliness and patients' acceptance of AirFluSal Forspiro in the treatment of asthma under real-life conditions (ASSURE). Pragm Observ Res. 2019; 10: 29-39.
ORCID

A. Emeryk - ID - http://orcid.org/0000-0003-1853-8696

J. Emeryk-Maksymiuk - ID - http://orcid.org/0000-0003-2709-0424

K. Janeczek - ID - http://orcid.org/0000-0002-8163-873X

Wkład autorów/Authors' contributions:

A. Emeryk: koncepcja, pisanie pracy, zebranie piśmiennictwa, redakcja manuskryptu; J. Emeryk-Maksymiuk: koncepcja, redakcja manuskryptu; K. Janeczek: pisanie pracy; K. Grzywna: zebranie piśmiennictwa, redakcja manuskryptu.

Konflikt interesów/Conflict of interests:

Nie występuje.

Finansowanie/Financial support:

Nie występuje.

Etyka/Ethics:

Treści przedstawione w artykule są zgodne z zasadami Deklaracji Helsińskiej, dyrektywami EU oraz ujednoliconymi wymaganiami dla czasopism biomedycznych.

Copyright: (C) Medical Education sp. z 0.0. This is an Open Access article distributed under the terms of the Attribution-NonCommercial 4.0 International (CC BY-NC 4.0). License (https://creativecommons.org/licenses/by-nc/4.0/), allowing third parties to copy and redistribute the material in any medium or format and to remix, transform, and build upon the material, provided the original work is properly cited and states its license.

Adres do korespondencji

prof. dr hab. n. med. Andrzej Emeryk

Klinika Chorób Płuc i Reumatologii Dziecięcej, Uniwersytet Medyczny w Lublinie 20-093 Lublin, ul. prof. Antoniego Gębali 6 tel.: (+48) 817185477

e-mail: emerykandrzej@gmail.com 